https://helda.helsinki.fi

\title{
Meta-analysis on vitamin $\mathrm{C}$ and the common cold in children may be misleading
}

\section{Hemilä, Harri}

2019-12

Hemilä , H \& Chalker , E 2019 , ' Meta-analysis on vitamin C and the common cold in children may be misleading ' , European Journal of Clinical Pharmacology , vol. 75 , no. 12 , pp. 1747-1748 . https://doi.org/10.1007/s00228-019-02733-x

http://hdl.handle.net/10138/318103

https://doi.org/10.1007/s00228-019-02733-x

acceptedVersion

Downloaded from Helda, University of Helsinki institutional repository.

This is an electronic reprint of the original article.

This reprint may differ from the original in pagination and typographic detail.

Please cite the original version. 
Harri Hemilä ${ }^{1}$ and Elizabeth Chalker ${ }^{2}$

${ }^{1}$ Department of Public Health, University of Helsinki, Helsinki, Finland

${ }^{2}$ University of Sydney, Sydney, Australia

Harri Hemilä, MD, PhD

http://orcid.org/0000-0002-4710-307X

Department of Public Health,

University of Helsinki, POB 41,

Helsinki, FI-00014, FINLAND.

harri.hemila@,helsinki.fi

Tel: +358-415329987

2019-5-16

Letter to the editor

Published in

European Journal of Clinical Pharmacology

as:

https://doi.org/10.1007/s00228-019-02733-x

https://www.ncbi.nlm.nih.gov/pubmed/31377890

A supplementary file is added to the end of this document.

This is a comment on:

Vorilhon P, Arpajou B, Vaillant Roussel H, Merlin É, Pereira B, Cabaillot A (2019)

Efficacy of vitamin $\mathrm{C}$ for the prevention and treatment of upper respiratory tract infection: a metaanalysis in children. Eur J Clin Pharmacol 75:303-311.

https://doi.org/10.1007/s00228-018-2601-7

https://www.ncbi.nlm.nih.gov/pubmed/30465062

A response to this letter was published by Vorilhon et al.

https://doi.org/10.1007/s00228-019-02734-w

https://www.ncbi.nlm.nih.gov/pubmed/31463576 
We are authors of a large Cochrane review on vitamin $\mathrm{C}$ and the common cold [1]. Our review includes 63 parallel comparisons of vitamin $\mathrm{C}$ and placebo reported in 44 publications [1]. We drew several conclusions from the large set of trials. However, there may be issues that we did not cover, and further analysis of the large set of data is welcome. In this journal, Vorilhon et al. reported a meta-analysis in which they examined the effect of vitamin $\mathrm{C}$ on common cold in children [2]. Nevertheless, we do not consider that their conclusions are valid. Our main concerns are summarized below. We include further issues and details in a supplementary file (see below).

1. The authors stated "All trials ... comparing the use of vitamin $\mathrm{C}$ against placebo were selected" [2]. However, one of the included trials administered vitamin C with echinacea and propolis [3]. That trial showed significant preventive effects in Vorilhon's Figure 2, and by far the greatest effects on the duration of colds in Figure 3. However, there is no basis to attribute the benefits to vitamin $\mathrm{C}$ specifically. For example, one meta-analysis concluded that "prophylactic treatment with Echinacea products was associated with a reduced risk of experiencing a cold ... P $<$ 0.001" [4]. Propolis may also influence infections. A meta-analysis on vitamin C should restrict to trials of vitamin $\mathrm{C}$ only [1].

2. Vorilhon wrote that "All trials qualifying as randomized clinical trials (RCTs) ... were selected." However, Coulehan (1974) did not use randomization: "All children were assigned alternately, from an alphabetical listing by classroom, to one of two study groups" [5, p 7]. In the Cochrane Handbook, which was also cited by Vorilhon [2], alternative allocation is classified as an "inadequate method of sequence generation" [6]. A meta-analysis restricted to randomized trials should exclude Coulehan (1974), but, if it is included, the review should not state that it restricts to randomized trials.

3. Ludvigsson reported two separate trials [7], but Vorilhon [2] did not include the smaller "pilot" trial, although that was larger $(\mathrm{N}=158)$ than three included trials $(\mathrm{N}=39$ to 60$)$. In the supplementary file by Vorilhon, the Coulehan (1976) trial [8] is both excluded and included; and in Figure 2 it is included whereas in Figure 3 it is excluded though Coulehan published the outcomes shown in both figures. No justification is given for these inconsistencies [2].

4. Vorilhon [2] gave SD values for three comparisons from two reports [5,9] without describing their source. The original reports did not publish the SD values. Although it is appropriate to impute SD values [6], the methods should be described if imputation is used. Furthermore, for the Ritzel trial Vorilhon gave SD values that led to $\mathrm{P}=0.238$ in Figure 3 . However, Ritzel stated that the study groups significantly deviated one from another with " $\mathrm{P}<0.05$; t-distribution" [9]. Thus, Vorilhon's SD values are incompatible with the Ritzel report.

5. In the Results section, Vorilhon wrote: "the duration of URTI was decreased by 1.6 days $(26 \%)$ in the vitamin C group" [2]. The calculation of this result was not reported. Figure 3 is the forest plot for the analysis of cold duration on the SMD (standardized mean difference) scale, which means the calculation of the effect in the SD units. However, the effect in SD units does not transform to an effect in days or \%-units.

6. The assessment of methodological quality was inconsistent. In Table 2, Vorilhon put a question mark for "incomplete outcome data" for the Ludvigsson trial, which indicates that there is potential bias. Ludvigsson reported that 96\% (615/642) of participants continued to the end of the "main" trial [7]. In contrast, Vorilhon did not question the Coulehan (1974) trial, which reported "Six hundred and forty-one of the 666 children (96 per cent) completed the entire 14-week study period" $[5$, p. 7]. These two trials had identical dropout rates, but they were assessed differently.

7. Vorilhon et al. allege our 2013 review [1] had limitations. In the introduction, they write: "A meta-analysis from 2013 assessed the efficacy of vitamin C for prevention and treatment of the common cold, but the review had limitations: ... it included one trial that contained manifestly incorrect data" [2, p. 304]. However, Vorilhon did not explain what they meant by that statement, which particular trial "contained manifestly incorrect data", or how the data was incorrect. This is a strong accusation about the validity of our review which we consider is unjustified. 


\section{References}

1. Hemilä H, Chalker E (2013) Vitamin C for preventing and treating the common cold. Cochrane Database Syst Rev CD000980.

https://doi.org/10.1002/14651858.CD000980.pub4 https://helda.helsinki.fi/handle/10138/225864

2. Vorilhon P, Arpajou B, Vaillant Roussel H, Merlin É, Pereira B, Cabaillot A (2019) Efficacy of vitamin $\mathrm{C}$ for the prevention and treatment of upper respiratory tract infection: a metaanalysis in children. Eur J Clin Pharmacol 75:303-311. https://doi.org/10.1007/s00228-018-2601-7

3. Cohen HA, Varsano I, Kahan E, Sarrell EM, Uziel Y (2004) Effectiveness of an herbal preparation containing echinacea, propolis, and vitamin $\mathrm{C}$ in preventing respiratory tract infections in children: a randomized, double-blind, placebo-controlled, multicenter study. Arch Pediatr Adolesc Med 158:217-21. https://doi.org/10.1001/archpedi.158.3.217

4. Karsch-Völk M, Barrett B, Kiefer D, Bauer R, Ardjomand-Woelkart K, Linde K (2014) Echinacea for preventing and treating the common cold. Cochrane Database Syst Rev CD000530. https://doi.org/10.1002/14651858.CD000530.pub3

5. Coulehan JL, Reisinger KS, Rogers KD, Bradley DW (1974) Vitamin C prophylaxis in a boarding school. N Engl J Med 290(1):6-10. https://doi.org/10.1056/NEJM197401032900102

6. Cochrane Handbook for Systematic Reviews of Interventions [Version 5.1.0; March 2011], sections 8.9.2.2. and 16.1.3.1. http://training.cochrane.org/handbook

7. Ludvigsson J, Hansson LO, Tibbling G (1977) Vitamin C as a preventive medicine against common colds in children. Scand J Infect Dis 9:91-8. https://www.ncbi.nlm.nih.gov/pubmed/897573 https://www.mv.helsinki.fi/home/hemila/CC/Ludvigsson 1977 ch.pdf

8. Coulehan JL, Eberhard S, Kapner L, Taylor F, Rogers K, Garry P (1976) Vitamin C and acute illness in Navajo school children. N Engl J Med 295:973-7. https://doi.org/10.1056/NEJM197610282951802

9. Ritzel G (1961) Critical evaluation of vitamin C as a prophylactic and therapeutic agent in colds. [in German]. Helv Med Acta 28:63-8. Translation available at: https://www.mv.helsinki.fi/home/hemila/T3.pdf https://www.ncbi.nlm.nih.gov/pubmed/13741912 https://www.mv.helsinki.fi/home/hemila/CC/Ritzel 1961 ch.pdf 


\title{
Meta-analysis on vitamin $\mathrm{C}$ and the common cold in children may be misleading
}

Harri Hemilä ${ }^{1}$ and Elizabeth Chalker ${ }^{2}$

1. Department of Public Health, University of Helsinki, Helsinki, Finland.

2. University of Sydney, Sydney, Australia.

Harri Hemilä, MD, PhD

Department of Public Health,

University of Helsinki, POB 41,

Helsinki, FI-00014, FINLAND.

harri.hemila@helsinki.fi

2019-7-30

Published in:

\section{European Journal of Clinical Pharmacology}

https://link.springer.com/journal/228

\author{
This is a Supplementary file \\ to our letter-to-the-editor \\ https://doi.org/10.1007/s00228-019-02733-X \\ commenting Vorilhon (2019) meta-analysis:
}

Vorilhon P, Arpajou B, Vaillant Roussel H, Merlin É, Pereira B, Cabaillot A. Efficacy of vitamin $\mathrm{C}$ for the prevention and treatment of upper respiratory tract infection. A meta-analysis in children.

Eur J Clin Pharmacol 2019;75(3):303-311

https://doi.org/10.1007/s00228-018-2601-7

https://www.ncbi.nlm.nih.gov/pubmed/30465062

Here we give additional information for the issues 1 to 6 listed in our letter-to-the-editor, and we also describe additional concerns from 7 to 13 . 


\section{Inclusion of a trial that did not study vitamin $\mathrm{C}$ alone}

Vorilhon wrote "All trials ... comparing the use of vitamin C against placebo were selected."

However, the included Cohen (2004) trial also administered echinacea and propolis to the "vitamin C" group. Thus, that is not a "vitamin C" trial but it is a "vitamin C + echinacea + propolis" trial and should not be included in an analysis of "vitamin C" alone.

https://doi.org/10.1001/archpedi.158.3.217

https://www.ncbi.nlm.nih.gov/pubmed/14993078

Vorilhon wrote "Cohen's RCT [23], ... While echinacea has not been shown to be effective in reducing the incidence and duration of URTIs [26]".

We do not consider that this statement justifies the inclusion of the Cohen trial, given that echinacea was administered with vitamin C. "Absence of evidence is not evidence of absence" is a basic principle in medical statistics, eg

https://www.ncbi.nlm.nih.gov/pubmed/8937675

https://www.ncbi.nlm.nih.gov/pubmed/14988165

https://www.ncbi.nlm.nih.gov/pubmed/25085689

Thus, "has not been shown to be effective" does not mean that echinacea "has been shown to be equivalent to placebo".

We believe, Vorilhon misrepresents the findings of the Cochrane review [ref 26 in their paper]. Echinacea is not a well-defined product, instead different trials have tested different kinds of echinacea extracts. In any case, the Cochrane review on echinacea and the common cold stated: "in our exploratory meta-analysis pooling all trials (1167 patients totally), regardless of the product used, prophylactic treatment with Echinacea products was associated with a reduced risk of experiencing a cold (RR 0.83, 95\% CI 0.75 to 0.92; P < 0.001)."

see page 13, left-hand column line 4 forward:

https://www.ncbi.nlm.nih.gov/pmc/articles/PMC4068831

Such very strong evidence for "prophylactic treatment with Echinacea products" refutes Vorilhon's assumption that echinacea is ineffective and can be administered with vitamin $\mathrm{C}$ without echinacea influencing the perceived vitamin $\mathrm{C}$ effect.

Furthermore, no justification is given for their assumption that propolis is an ineffective component of the Cohen trial. There are RCTs that have reported benefits of propolis:

"The administration of a propolis and zinc suspension to children with a history of rAOM [recurrent acute otitis media] can significantly reduce the risk of new AOM episodes."

https://www.ncbi.nlm.nih.gov/pubmed/20646352

"Propolis plus bicarbonate was safe, well tolerated and promisingly effective in the prevention of OM [oral mucositis] in patients with breast cancer."

https://www.ncbi.nlm.nih.gov/pubmed/28840622

"Propolis is produced by bees and is reported to have several pharmaceutical properties. Its antibacterial activity against strains causing upper respiratory tract infections is particularly important: propolis might be used as a therapeutic agent to prevent the bacterial infections that sometimes overlap viral infections."

https://www.ncbi.nlm.nih.gov/pubmed/16736885

"Propolis may have a role in the treatment of (aphthous) stomatitis, mouth ulcer and prevention of acute otitis media."

https://www.ncbi.nlm.nih.gov/pubmed/26453201

"Varicella zoster virus ... The propolis extract exhibited high levels of antiviral activity against $V Z V$ in viral suspension tests, infectivity was significantly reduced by $93.9 \%$ and a direct concentration-dependent antiviral activity could be demonstrated."

https://www.ncbi.nlm.nih.gov/pubmed/30522559 
Thus, there is no justification to assume that propolis is equivalent to placebo in a common cold trial.

When the selection criterion for trials is "RCTs comparing the use of vitamin $C$ against placebo", it is not appropriate to include a "vitamin C + echinacea + propolis" trial. It is not a "vitamin C" trial.

Furthermore, the Cohen RCT [23] is highly influential in Vorilhon's review.

The Cohen trial shows significant preventive effects in Vorilhon's Figure 2 and it is by far the most positive study in Figure 3. In addition, the Cohen trial is the only study that had children under 6 years (see Table 1 in Vorilhon).

In the Abstract, Vorilhon wrote "Children under 6 years of age benefit from more effective vitamin $C$ supplementation associated with echinacea" and in the Conclusion section they write "Vitamin C supplementation appears to be more effective for children under 6 years of age".

Those sentences are based fully on the Cohen trial, so that its exclusion would lead to a substantial revision of the conclusions even at the Abstract level. 


\section{Inclusion of a trial that was not a randomized trial}

In their statement of Study selection, Vorilhon wrote "All trials qualifying as randomized clinical trials $(R C T S)$... were selected."

The Coulehan (1974) trial was not randomized, but it was an alternative allocation trial (p 7):

All children were assigned alternately, from an alphabetical listing by classroom, to one of two study groups. A pharmacist, not other-

Coulehan JL, Reisinger KS, Rogers KD, Bradley DW. Vitamin C prophylaxis in a boarding school. N Engl J Med. 1974;290(1):6-10.

https://doi.org/10.1056/NEJM197401032900102

https://www.ncbi.nlm.nih.gov/pubmed/4586102

In the Cochrane Handbook, alternative allocation is classified under the subtitle "Inadequate methods of sequence generation". It is described with the comment "sometimes referred to as quasirandom":

https://handbook-5-1.cochrane.org/chapter_8/8_9_2_2_inadequate_methods_of_sequence_generation.htm

Vorilhon should have either excluded the Coulehan (1974) trial since it was not a randomized trial, or should have stated that quasi-randomized trials were included.

Vorilhon's ref 13 is the same Cochrane Handbook to which we give the link above. In the Methods section (p. 304) Vorilhon wrote "This study followed ... Cochrane Handbook guidance standards [13]" but that did not occur in the selection of trials process. 


\section{3a) Exclusion of the Ludvigsson "pilot" study without justification}

Ludvigsson (1977). reported two separate trials, the "pilot" trial and the "main" trial, but Vorilhon included only the "main" trial and not the "pilot" trial.

Ludvigsson J, Hansson LO, Tibbling G. Vitamin C as a preventive medicine against common colds in children. Scand J Infect Dis. 1977;9(2):91-8.

https://www.ncbi.nlm.nih.gov/pubmed/897573

https://www.mv.helsinki.fi/home/hemila/CC/Ludvigsson 1977 bm.pdf

https://www.mv.helsinki.fi/home/hemila/CC/Ludvigsson_1977_ch.pdf

In Table 1, Vorilhon writes of the Ludvigsson (1977) trial: " 1 g/day in the intervention group and $30 \mathrm{mg} /$ day of vitamin $C$ in the placebo group for the pilot study during 7 weeks" as one paragraph and " $1 \mathrm{~g} /$ day in the intervention group and $10 \mathrm{mg} /$ day of vitamin $C$ in the placebo group for the main study during 12 weeks" in another paragraph.

In the Discussion, Vorilhon write (p. 310) that "In the RCT by Ludvigsson et al. [20], the placebo contained a small dose of vitamin C $(10 \mathrm{mg}$ in the main study and $30 \mathrm{mg}$ in the pilot study)." Thus, Vorilhon recognized that there were two separate RCTs reported in the Ludvigsson paper (ie the "main" and "pilot" trials).

Ludvigsson reported (p. 95):

The "pilot study" had $78+80=158$ participants

The "main study" had $311+304=615$ participants

Only the "main study" is included in Vorilhon Figures 2 and 3.

In systematic reviews, all identified relevant RCTs should be either rejected with an explicit reason, or they should be included in the analysis.

The paper and supplementary file of Vorilhon do not give any justification for excluding the "pilot study" of Ludvigsson from the forest plots presented in Figure 2 and Figure 3.

This is not a trivial issue. Although the 158 participants was a "pilot study" for Ludvigsson (1977), the 158 participants is considerably more than the number of participants:

$\mathrm{N}=62$ in Bancalari

$\mathrm{N}=39$ in Constantini

$\mathrm{N}=88$ (=44 twin pairs) in Miller; (see Table 1 of the Vorilhon paper).

\section{3b) Simultaneous inclusion and exclusion of the Coulehan (1976) trial}

The Coulehan (1976) trial

http://dx.doi.org/10.1056/NEJM197610282951802

https://www.ncbi.nlm.nih.gov/pubmed/787788

is both excluded and included in the supplementary file for the Vorilhon paper.

It is listed in Supplement Table 5: "Qualitative analysis of excluded trials"

but it is also listed in Supplement Table 6: "Risk of bias in the [included] studies"

In the Results section of the Vorilhon paper, the Coulehan (1976) trial is included in Figure 2 which describes the incidence of colds, but it is not included in Figure 3 which describes the duration of colds, although Coulehan (1976) reported the duration of colds even in their Abstract:

"There was no difference in ... mean illness duration (5.5 versus 5.8 days) between the [vitamin C and placebo] groups" https://www.ncbi.nlm.nih.gov/pubmed/787788

Vorilhon does not give an explanation as to why this trial is both excluded and included in the supplement, and why it is included in Figure 2 but not in Figure 3. 


\section{SD values without sources}

\section{4a) SD values for the Coulehan (1974) trials with 1 and 2 g/day of vitamin C}

In Table 3, Vorilhon stated that the SD values for the Coulehan (1974) trial were 4.8 days in the treated (vitamin C) groups and 6.4 days in the control (placebo) groups for both the $1 \mathrm{~g} /$ day and the $2 \mathrm{~g} /$ day dosage.

Coulehan JL, Reisinger KS, Rogers KD, Bradley DW. Vitamin C prophylaxis in a boarding school. N Engl J Med. 1974;290(1):6-10. https://doi.org/10.1056/NEJM197401032900102

http://www.ncbi.nlm.nih.gov/pubmed/4586102

Coulehan (1974) reported the duration of "respiratory illness" as follows in Table 2 (below): 4.95 days and 5.65 days for the Lower grades children ( $1 \mathrm{~g}$ group in Vorilhon Fig. 3 ). and

4.44 days and 6.29 days for the Upper grades children (2 g group in Vorilhon Fig. 3). However, Coulehan (1974) did not report the SD for the above-mentioned mean values:

Table 2. Clinical Episodes of Illness and Days of Morbidity.

\begin{tabular}{|c|c|c|c|c|c|}
\hline GrouP & $\begin{array}{l}\text { No. OF } \\
\text { CHILDREN }\end{array}$ & $\begin{array}{l}\text { No. OF } \\
\text { EPISODES }\end{array}$ & $\begin{array}{c}\text { DAYS OF } \\
\text { MORBIDITY } \\
\text { FROM ALL } \\
\text { EPISODES }\end{array}$ & $\begin{array}{l}\text { AveraGe } \\
\text { DURATION } \\
\text { OF EPISODES } \\
\text { (DAYS) }\end{array}$ & $\begin{array}{c}\text { CHANGE IN } \\
\text { DAYS OF } \\
\text { MoRBIDITY } \\
\text { ON VITAMIN } \\
(\%)\end{array}$ \\
\hline \multicolumn{6}{|c|}{ Respiratory illness: } \\
\hline $\begin{array}{l}\text { Vitamin C } \\
\text { Placebo }\end{array}$ & $\begin{array}{l}190 \\
192\end{array}$ & $\begin{array}{l}19 \\
23\end{array}$ & $\begin{array}{r}94 \\
130\end{array}$ & $\begin{array}{l}4.95 \\
5.65\end{array}$ & $-28 *$ \\
\hline \multicolumn{6}{|l|}{ Upper grades: } \\
\hline $\begin{array}{l}\text { Vitamin C } \\
\text { Placebo }\end{array}$ & $\begin{array}{l}131 \\
128\end{array}$ & $\begin{array}{l}16 \\
17\end{array}$ & $\begin{array}{r}71 \\
107\end{array}$ & $\begin{array}{l}4.44 \\
6.29\end{array}$ & $-34^{\dagger}$ \\
\hline \multicolumn{6}{|l|}{ Other illness: } \\
\hline $\begin{array}{l}\text { Vitamin C } \\
\text { Placebo }\end{array}$ & $\begin{array}{l}190 \\
192\end{array}$ & $\begin{array}{l}25 \\
26\end{array}$ & $\begin{array}{l}108 \\
154\end{array}$ & $\begin{array}{l}4.32 \\
5.92\end{array}$ & $-30 *$ \\
\hline \multicolumn{6}{|l|}{ Upper grades: } \\
\hline $\begin{array}{l}\text { Vitamin C } \\
\text { Placebo }\end{array}$ & $\begin{array}{l}131 \\
128\end{array}$ & $\begin{array}{l}19 \\
19\end{array}$ & $\begin{array}{l}115 \\
125\end{array}$ & $\begin{array}{l}6.05 \\
6.58\end{array}$ & -8 \\
\hline
\end{tabular}

$* 3 \times 2$ table comparing days of respiratory illness, days of other illness \& days not known to be ill; chi-square $=13.20 ; 2 \mathrm{df}, \mathrm{p}<0.01$.

${ }^{\dagger}$ As above, chi-square $=8.93 ; 2 \mathrm{df}, \mathrm{p}<0.05$.

In a meta-analysis, it is appropriate to "impute" variables such as SD and SE. For example, if the mean difference and the P-value are reported, the SE value can be calculated as an "imputed" value (a P-value can be back-transformed to a $\mathrm{z}$ or t-value), even when the SE was not reported. This is described in the Cochrane Handbook section 16.1.3.1 on "Imputing standard deviations": https://handbook-5-1.cochrane.org/chapter_16/16_1_3_1imputing_standard_deviations.htm

However, if imputation of SD values is used, the researchers should describe the method of imputation, but none was given by Vorilhon. There is no description in their paper about the source of the SD values 4.8 and 6.4 days for the Coulehan (1974) trial and it is not clear how they were calculated. 


\section{4b) SD values for the Ritzel trial}

For the Ritzel (1961) trial, Vorilhon reported the SD values as 4.8 days in the treated (vitamin C) groups and 6.4 days in the control (placebo) groups. These figures gave $\mathrm{P}=0.238$ in Figure 3 of the Vorilhon paper.

Ritzel G. Critical evaluation of vitamin $\mathrm{C}$ as a prophylactic and therapeutic agent in colds.

[in German]. Helv Med Acta. 1961;28:63-8.

http://www.mv.helsinki.fi/home/hemila/CC/Ritzel_1961_ch.pdf

http://www.mv.helsinki.fi/home/hemila/CC/Ritzel_1961_bm.pdf

http://www.ncbi.nlm.nih.gov/pubmed/13741912

https://www.mv.helsinki.fi/home/hemila/T3.pdf Translation

Ritzel published the results as follows:

In diesem Zusammenhang schien uns auch die Auswertung der Ergebnisse nach der therapeutischen Seite von Interesse. Dazu verglichen wir die mittlere Erkrankungsdauer beider Gruppen. Sie betrug beim vitamin-Cbehandelten Kollektiv 1,8, bei den Patienten, die Placebo erhielten, hingegen 2,6 Tage. Auch diese Durchschnitte weichen statistisch wesentlich voneinander ab $(\mathrm{P}<0,05$; t-Verteilung).

Translation:

"In this connection, too, evaluation of the results from the therapeutic perspective appeared to us to be of interest. In this regard we compared the average length of sickness for both groups. In the case of the group treated with vitamin $C$ it was 1.8 days versus 2.6 days for the group that received placebos. These averages, too, deviate statistically significantly one from the other $(P<$ 0.05; t-distribution)." see: https://www.mv.helsinki.fi/home/hemila/T3.pdf

Ritzel does not report SD values in that section of text, nor in any other part of the 1961 report. Here it is obvious that the SD values published by Vorilhon cannot originate from imputation, since Vorilhon's resulting $\mathrm{P}$-value $(\mathrm{P}=0.238)$ is inconsistent with the $\mathrm{P}$-value published by Ritzel $(\mathrm{P}<$ 0.05). If imputation is used, the imputed SD values should be consistent with the published $\mathrm{P}$-value.

It is also quite surprising that the SD values for the Ritzel trial are identical to the SD values for both the $1 \mathrm{~g}$ and the $2 \mathrm{~g}$ trials of the Coulehan (1974) report, i.e. SD 4.8 days in the treated (vitamin C) groups and SD 6.4 days in the control (placebo) groups for each of the three trials. If imputation was used, it is highly unlikely that the calculated SD values would be identical in three trials. 
5. "Vitamin C administration was found to decrease the duration of URTI by 1.6 days" (Abstract, Vorilhon)

"the duration of URTI was decreased by 1.6 days (26\%) in the vitamin C group"

(Results, Vorilhon)

"Vitamin C administration decreased the duration of URTI by 1.6 days" and

"a decrease of 1.6 days of URTI may represent a potential reduction in the inappropriate prescribing of ineffective or even potentially dangerous antibiotics"

(Discussion, Vorilhon)

There is no reported calculation or forest plot in the paper, which describes the origin of the reported 1.6 day and $26 \%$ effect.

Figure 3 is the forest plot for the analysis on the SMD (standardized mean difference) scale, which means the calculation of the vitamin C effect in SD units. However, the effect in SD units does not transform to the effects in days or \%-units. If a researcher is interested in the effect of vitamin $\mathrm{C}$ on the duration in days, then the meta-analysis must be carried out on the days scale, and if the researcher is interested in the \%-effects, then the meta-analysis needs to be done on the relative scale.

For example, let us assume that there are two trials that observe identical common cold duration in two study groups, 6 days for the vitamin $C$ groups and 7 days for the placebo groups. This means that both trials show that vitamin $\mathrm{C}$ reduces the length of colds by one day (or 14\%). However, if one of the two studies has more homogeneous common cold durations, which means a smaller SD, whereas the other study has more heterogeneous common cold durations, which means a larger SD, then the two trials show substantially different treatment effects on the SMD-scale, even though the effect on the "days" scale and the \%-scale was identical.

The converse is also true. Thus, studies with an identical effect on the SMD-scale can have substantially different effects on the "days" and \%-scales. Therefore, an effect on the SMD-scale cannot be transformed to a days effect or a percentage effect.

Vorilhon does not describe the statistical origin for the reported 1.6 days and the $26 \%$ effects. The 1.6 day value is published in the Abstract, so that the validity of this estimate is important even for the validity of the Abstract. 


\section{Assessment of methodological quality is inconsistent}

In Table 2 (risk of bias summary), Vorilhon put a question mark for "Incomplete outcome data" for the Ludvigsson (1977) trial, but not for the Coulehan (1974) trial. A question mark indicates that that there is potential bias in the quality item.

Ludvigsson wrote that in their "main study" (p. 91):

\section{Of 719 pupils asked, 642 took part, and of those 615 completed the study (Table I).}

Thus, $96 \%$ of participants who took part (615/642), continued to the end of the trial.

In the supplementary file, Vorilhon wrote about the Ludvigsson trial:

"Losses to follow-up were high and it is not known whether this affects one group more than the other."

Vorilhon does not give a quantitative justification for this statement.

There does not seem to be any basis to claim that a $4 \%$ drop-out rate in a 3-month trial is so high that it is likely to cause substantial bias in the findings.

Coulehan (1974) wrote (p. 7):

\section{Results \\ Six hundred and forty-one of the 666 children (96 per cent) completed the entire 14-week study period.}

Thus, the Ludvigsson (1977) "main" trial and the Coulehan (1974) trial both had the same 4\% drop-out rate (which is very low), but Vorilhon considered that the $4 \%$ dropout was a problem in the Ludvigsson trial, but not in the Coulehan (1974) trial, without any justification for the inconsistency.

In Table 2 (Risk of bias table), Vorilhon puts a question mark for "blinding of participants and personnel" for Bancalari, Constantini, Cohen and Miller trials.

However, in the Results section "Trials included" (p. 305), Vorilhon writes

"Eight double-blind RCTs met the inclusion criteria... The trials were randomized, placebocontrolled, and double-blind."

Double blind means that both the participants and the researchers were blinded.

Given that Vorilhon described the trials as "placebo-controlled, and double-blind", there should be an explanation as to why they put question marks against this quality item. No justification is provided in the supplementary file. 


\title{
7) Vorilhon alleges our 2013 Cochrane review had limitations
}

\author{
Our Cochrane review: \\ https://doi.org/10.1002/14651858.CD000980.pub4 \\ https://helda.helsinki.fi/handle/10138/225864 \\ http://www.mv.helsinki.fi/home/hemila/CC/2013_Coch_Colds_CD000980.pdf
}

7a) In the Introduction (p 304) Vorilhon refers to our Cochrane review [ref 11 in Vorilhon]:

"A meta-analysis from 2013 assessed the efficacy of vitamin $C$ for prevention and treatment of the common cold [11], but the review had limitations: ... (2) it included one trial that contained manifestly incorrect data."

However, Vorilhon did not describe what they mean by that statement, either in their paper or in the supplement. They did not report which particular trial "contained manifestly incorrect data", and how the data was incorrect.

This is a strong accusation about the validity of our Cochrane review indicating that we have been sloppy. Given the lack of any specific description about the identity of the trial, and the kind of "manifestly incorrect data" in that particular trial, we consider that this is an unjustified accusation. If Vorilhon has knowledge that we are unaware of about one of our included trials, we would be very keen to learn of it.

7b) In the Introduction (p 304) Vorilhon refers to our Cochrane review [ref 11 in Vorilhon]:

"A meta-analysis from 2013 assessed the efficacy of vitamin C for prevention and treatment of the common cold [11], but the review had limitations: (1) it did not specifically evaluate the effect of vitamin C on the incidence of URTI in children and adolescents."

Vorilhon uses this statement as a justification for their analysis of vitamin $\mathrm{C}$ on common cold incidence in children. However, in our Cochrane review we showed that there was statistically significant heterogeneity over 29 trials on adults and children $(\mathrm{P}=0.02$ in the heterogeneity test). We showed that the heterogeneity was explained by the experimental conditions. In trials carried out in the general community, there was no evidence that vitamin $\mathrm{C}$ influenced the incidence of colds, with $\mathrm{RR}=0.97$ (95\% CI 0.94 to 1.00$)$. In contrast, in five trials carried out with participants under heavy short-term physical stress, vitamin $\mathrm{C}$ reduced the incidence of colds by $\mathrm{RR}=0.48$ (95\% CI 0.35 to $0.64 ; \mathrm{z}=4.00, \mathrm{P}<0.00001)$. The Ritzel (1961) trial with schoolchildren in a short skiing camp in Swiss Alps falls to the latter group of five trials. Thus, the benefit reported by Ritzel seemed to be explained by the harsh conditions of the skiing camp, and not by the young age of the participants. The set of 24 trials with participants in the "general community" includes several trials with children, with all of them being consistent with the lack of effect.

Although further research on vitamin $\mathrm{C}$ and common cold incidence is welcome, new research should take into account the findings of previous meta-analyses, such as the effect of heavy shortterm physical stress in the analysis on vitamin $\mathrm{C}$ and common cold incidence. 
7c) In the Discussion (p 309) Vorilhon refers to our Cochrane review [ref 11 in Vorilhon]:

"It is noteworthy that Hemilä's review and analysis did not distinguish between children and adults with regard to the primary endpoint, but only with regard to the secondary endpoints. If the data on the primary endpoint are stratified to separate children and adults, the preventive effect of vitamin $C$ is no longer found in children $(p=0.42)$."

It is not clear to us, what Vorilhon means with the statement "If the data on the primary endpoint are stratified to separate children and adults, the preventive effect of vitamin $C$ is no longer found in children $(p=0.42) . "$

When all 29 preventive vitamin $\mathrm{C}$ trials were pooled in the Cochrane review, we calculated $\mathrm{RR}$ $=0.95$ (95\% CI 0.92 to 0.98). We commented "Although the overall difference between vitamin C and placebo participants is statistically highly significant $(P=0.001)$, indicating a biological effect of vitamin $C$, the narrow CI precludes any clinically relevant effect over wide population groups" (p. 12).

Thus, we stated that such a narrow confidence interval close to the null effect did not indicate any practical benefits of vitamin $\mathrm{C}$. Therefore, we cannot understand what Vorilhon meant by "the preventive effect of vitamin C is no longer found in children" when we had not proposed that there might be a meaningful preventive effect of vitamin $C$ for children and adults over all 29 trials.

As described above in $7 \mathrm{~b}$, in our Cochrane review we showed that physical stress explained the significant heterogeneity over the 29 trials. Given this, the prevention trials should first be stratified by physical stress, and secondarily by children and adults. However, in the general community trials, we found that there was no preventive effect from vitamin $\mathrm{C}$ for trials in children or adults. In the five physical stress trials, the trials in both children (i.e. the Ritzel trial) and adults are consistent with vitamin $\mathrm{C}$ halving common cold incidence. Therefore, stratifying by age (children/adults) does not give any additional information after the stratification by the heavy short-term physical stress.

Thus, Vorilhon misunderstands our findings on the role of physical stress and leads the reader to believe that the children vs. adult stratification may have influenced our conclusions. This is not correct. 


\section{8) Vorilhon used OR (odds ratio) for estimating the preventive effect of vitamin C}

In Figure 2, Vorilhon used the OR scale to calculate the effect of vitamin $\mathrm{C}$ on common cold incidence. OR is a useful approximation of RR in case-control studies. However, this approximation is only valid for rare events. Common cold events are not rare. Furthermore, for RCT results there is no reason to calculate the OR estimates, since the RR can be directly calculated from the RCT results, which is not the case for case-control results.

For example, Altman wrote that "the odds ratio [OR] should not be interpreted as an approximate relative risk [RR] unless the events are rare in both groups (say, less than 20-30\%)" https://www.bmj.com/content/317/7168/1318.1

In the Bancalari trial, the incidence of colds was 21/32 (66\%) in the vitamin $C$ group and 21/30 $(70 \%)$ in the placebo group.

In the Ludvigsson "main" trial, the incidence of colds was 230/304 (75\%) in the vitamin C group and 240/311 (77\%) in the placebo group.

These incidence levels are much higher than the upper limit suggested by Altman. 


\section{9) The data used by Vorilhon for calculating Ritzel trial OR appears inconsistent with the published Ritzel results}

In Figure 2, Vorilhon calculated that the incidence of colds was decreased in the Ritzel trial by $\mathrm{OR}=0.36(95 \%$ CI 0.23 to 0.54$)$.

In our Cochrane (2013) review, we state that the Ritzel trial had 17 colds in 139 vitamin $C$ participants, and 31 colds in 140 placebo participants. The 17 and 31 colds were not reported by Ritzel, but we derived them using the following calculation.

In Table 1 (below), Ritzel reported that there were 31 sickness days in the vitamin $\mathrm{C}$ group. In the text section Ritzel reported that the duration of colds was 1.8 days in the vitamin $\mathrm{C}$ group (see p. 7 of this text)

Tabelle 1

Erkältungsprophylaxe durch Vitamin C (1,0 g täglich): Häufigkeit der Krankheitstage und Einzelsymptome im Vergleich zu einem scheinbehandelten Kollektiv

\begin{tabular}{l|c|c|c}
\hline & $\begin{array}{c}\text { Mit Vitamin C } \\
\text { behandelt }\end{array}$ & $\begin{array}{c}\text { Placebo } \\
\text { verabreicht }\end{array}$ & Total \\
\hline Anzahl Versuchsteilnehmer ..... & 139 & 140 & 279 \\
Anzahl Krankheitstage ........ & 31 & 80 & 111
\end{tabular}

The study lasted over "5 to 7 day long ski camps" (1st paragraph of Results in the Ritzel report) and thus it is reasonable to assume that there was not more than 1 cold episode per person during such a short trial in a skiing camp.

This gives, $31 / 1.8=17.2$ colds in the vitamin $\mathrm{C}$ group.

Similarly, 80/2.6 $=30.8$ colds in the placebo group.

These round to 17 and 31, which we use as estimates for the number of colds in our Cochrane review.

Calculation of the OR for the above data gives

$\mathrm{OR}=[17 /(139-17)] /[31 /(140-31)]=[17 / 122] /[31 / 109]=0.139 / 0.284=0.49$.

In Figure 2, Vorilhon reports that the effect of vitamin $\mathrm{C}$ in the Ritzel trial was $\mathrm{OR}=0.36$.

We suspect that the $\mathrm{OR}=0.36$ is erroneous. It is inconsistent with the incidences that we describe above. Vorilhon does not describe how they extracted the incidence data for the Ritzel trial, which they used in the calculation of their $\mathrm{OR}=0.36$.

Furthermore, the confidence interval that Vorilhon reported, ie, (95\% CI 0.23 to 0.54 ) corresponds to $\mathrm{P}(2-\mathrm{t})=0.00003$.

This is based on the following calculation:

$\ln (0.54)-\ln (0.23)=2 * 1.96 * \mathrm{SE}$, which gives $\mathrm{SE}=0.218$

The OR-effect on the logarithmic scale is $\ln (0.36)=1.02=$ Effect

Thus, $\mathrm{z}=\mathrm{Effect} / \mathrm{SE}=1.02 / 0.218=4.69$, which corresponds to $\mathrm{P}(2-\mathrm{t})=0.000003$.

However, the Fisher exact test for the $2 \times 2$ table [17/122]/[31/109] gives $\mathrm{P}=0.0385$.

This can be calculated with various web-based calculators, eg.

https://www.socscistatistics.com/tests/fisher/default2.aspx

https://www.graphpad.com/quickcalcs/contingency2

http://vassarstats.net/tab2 2. html 
The 95\% CI for the OR can also be calculated for [17/122]/[31/109], http://vassarstats.net/odds $2 \times 2 . h t m l$

giving

OR 0.49 (95\% CI 0.26 to 0.93 ), which is quite close to the RR that we calculated in our Cochrane review: RR 0.55 (95\% CI 0.32 to 0.95 ).

Thus, there seem to be significant errors in the calculation of the OR of the Ritzel trial by Vorilhon.

Overall, Vorilhon do not describe in their paper or in their supplementary file the extracted incidence values for the Figure 2 trials. For the transparency of a meta-analysis it is essential that the extracted data are described so that a critically minded reader can check the data and the statistical processes. 


\section{0) Incorrect statement about the Ritzel trial}

Vorilhon wrote "It was not possible to obtain individual-level data from Ritzel et al.; in their $R C T$, the results were reported in sickness days and it was not possible to extract or analyze the data" (p. 309).

This sentence misleads the reader. There are no individual-participant data (IPD) for any of the old trials: Coulehan (1974), Coulehan (1976), Ludvigsson (1977), Miller (1977), Bancalari (1984). There are only mean values for the vitamin C and placebo groups, with SD for some trials but not for all. In addition, Vorilhon does not describe that they have used IPD in any analyses of the other trials. Thus, the existence, or lack of existence, of IPD for the Ritzel trial has no consequences.

Vorilhon's statement makes the reader believe that the Ritzel trial is particularly poor. The Ritzel trial was published in 1961 and the standards of reporting were very different compared with current standards. However, the Ritzel trial should not be singled out for the lack of IPD when that is not available for other trials, and when Vorilhon does not report any analyses of IPD.

Furthermore, Vorilhon does include the Ritzel trial in both Figure 2 and Figure 3 and thus it was "possible to extract and analyze the data" although the above sentence claims that it was not possible to extract or analyze the Ritzel data. 


\section{1) No consideration about the complexity of the common cold}

Vorilhon writes in the Abstract:

"Vitamin C administration was found to decrease the duration of URTI by 1.6 days" and in the Discussion:

"For an average duration of 6 days, a decrease of 1.6 days of URTI may represent a potential reduction in the inappropriate prescribing of ineffective or even potentially dangerous antibiotics"

As described above, the 1.6 days estimate is not based on any reported statistical analysis.

However, even if the 1.6 days was a valid estimate, the interpretation of such an estimate is not straightforward and should be considered thoroughly in the Discussion.

The Ludvigsson (1977) "main" trial is particularly informative on this issue.

In the "main study" (p. 95) with 615 participants, Ludvigsson found no effect on:

"cold symptoms from the nose" or

"upper respiratory tract infection"

However, Ludvigsson found a significant $(\mathrm{t}=2.42, \mathrm{P}=0.016)$ effect on:

"absence from school because of URTI"

The effect of vitamin $\mathrm{C}$ was a 0.45 day (14\%) reduction in days absent from school (2.77 days in the vitamin $\mathrm{C}$ group vs. 3.22 days in the placebo group)

Thus, the effect of vitamin $\mathrm{C}$ may be different depending on the particular common cold outcome. A large trial by Terrence Anderson (1972) with adults also found a significant $(\mathrm{t}=2.45$, $\mathrm{P}=0.014$ ) effect on time "confined indoors", but no effect on the "duration of symptoms" (Table II). Anderson (1972) found a 0.28 day reduction in "days confined indoors" (1.04 days in the vitamin $\mathrm{C}$ group vs. 1.32 days in the placebo group).

https://www.ncbi.nlm.nih.gov/pmc/articles/PMC1940935

If the symptoms are mild, such that the patient has a runny nose but can go to school or work without functional limitations, reduction in the duration of runny nose by, say, 1.6 days might not have practical consequences.

On the other hand, if "days off school" or "days confined indoors" is shortened by 1.6 days per episode, that might be a substantial effect. However, there is no basis to assume that the 1.6 days is a reasonable estimate for the effect of vitamin C on "days off school". The most informative estimate for the effect on "days off school" is from the Ludvigsson (1977) "main trial" which is a reduction of 0.45 days which is much smaller than 1.6 days.

Furthermore, the cost-benefit should be considered. Does a child need to take vitamin $C$ for half a year to shorten "days off school" by half a day? What is the cost of taking vitamin $\mathrm{C}$ for half a year? Vorilhon ignores the complexity of "the common cold". 


\section{2) Many numbers are inconsistent in different parts of the paper}

Figure 1 (the flow chart) describes that 7 trials were included in the quantitative analysis.

Table 1 lists 8 trials in the "Authors" and "No [the number of] participants" columns, but 9 trials in the "doses and duration" column. This discrepancy is explained by mentioning the Ludvigsson "pilot" study in "doses" but not in "No participants".

Figure 2 has 7 trials with Coulehan (1974) as a single trial and the Miller trial excluded and Figure 3 has 8 trials with Coulehan (1974) as two trials and the Coulehan (1976) excluded.

The abstract states "Eight RCTs, including 3135 children"

The discussion states: "Statistical analysis of seven RCTs, including 3135 children"

Thus, the number of included trials varies between 7 and 9 . The number of included trials should be consistent throughout the article.

Furthermore, we calculated the number of participants in Table 1 from the "No participants":

$62+328+39+641+868+615+44+279=2876$.

Vorilhon states there are 3135 participants in the Abstract and Discussion, so there are 259 participants missing between the Abstract and Table 1.

The Results section states: "The dose of vitamin C varied from 0.5 to 2 g/day"

The Discussion states: "The vitamin $C$ dosage delivered differed between RCTs $(2$ g/day in Bancalari et al. [19] and $100 \mathrm{mg}$ in Cohen et al. [18])."

Thus, the lowest dose in the Results is $0.5 \mathrm{~g} /$ day but in the Discussion it is $0.1 \mathrm{~g} /$ day. This should also be consistent. 


\section{3) Erroneous statements in the Introduction, misleading the readers}

In the third paragraph Vorilhon writes:

"Vitamin C was used heavily in the 1970s in the wake of Pauling's clinical trials concluding that vitamin C prevents URTI and improves URTI symptoms [5-7]."

In actual fact, Pauling did not carry out any clinical trials on vitamin $\mathrm{C}$ and URTI. He published two meta-analyses of placebo-controlled trials carried out by other researchers, both were published in 1971:

https://dx.doi.org/10.1073\%2Fpnas.68.11.2678

https://dx.doi.org/10.1093/ajcn/24.11.1294

The three references at the end of the above sentence, i.e. [5-7], refer to papers by Terrence Anderson, then professor at the Department of Epidemiology and Biometrics, University of Toronto. Thus, they are not papers by Pauling, although the references at the end of the sentence makes the reader assume so:

[5] https://www.mv.helsinki.fi/home/hemila/CC/Anderson_1977.pdf

[6] https://www.ncbi.nlm.nih.gov/pmc/articles/PMC1947567

[7] https://www.ncbi.nlm.nih.gov/pmc/articles/PMC1958969

In the third paragraph Vorilhon continues:

"However, later trials failed to corroborate this preventive effect of vitamin $C$ supplementation [8-10]."

The three references 8-10 refer to two reviews published in 1975 ([8] Dykes 1975 and [9] Chalmers 1975 and) and one RCT published also in 1975 ([10] Karlowski 1975).

In our Cochrane review we briefly comment on those three papers from the year of 1975 as follows:

"In a meta-analysis, Chalmers 1975 calculated an unweighted average of the treatment effect in seven placebo-controlled trials and found that colds in vitamin C groups were $0.11 \pm 0.24$ (standard error (SE)) days shorter which is not a statistically or clinically significant difference. In a qualitative review on vitamin C and the common cold published in the same year, Dykes 1975 also concluded that vitamin $C$ had no effect on colds.

However, it has subsequently been pointed out that the influential reviews by Chalmers 1975 and Dykes 1975 contain serious errors (Hemilä 1995;Hemilä 1996c;Hemilä 2006a). Hemilä 1995 showed that after extraction of correct data from the trial reports, correction of errors in calculations, and restriction to trials in which at least $1 \mathrm{~g} /$ day of vitamin $C$ had been used, as Pauling had proposed, Chalmers 1975 would have calculated an eight times higher estimate of the vitamin C effect: $0.93 \pm 0.22$ (SE) days reduction in the duration of colds. Furthermore, both Chalmers 1975 and Dykes 1975 placed considerable weight on the double-blind, placebocontrolled trial carried out by Karlowski 1975a at the National Institutes of Health (NIH), which concluded that a statistically significant benefit of vitamin $C$ supplementation was simply explained by the placebo effect. However, it has been shown that the placebo effect explanation in the Karlowski 1975a paper was not consistent with their own data (Chalmers 1996; Hemilä1996a; Hemilä 1996d; Hemilä 2006a; Hemilä 2006c)"

see page 3, right-hand column: https://doi.org/10.1002/14651858.CD000980.pub4 https://www.mv.helsinki.fi/home/hemila/CC/2013 Coch Colds CD000980.pdf https://helda.helsinki.fi/handle/10138/225864 
The Dykes-Meier (1975) review [8]

http://dx.doi.org/10.1001/jama.1975.03240220051025

and

The Chalmers (1975) review [9]

http://dx.doi.org/10.1016/0002-9343\%2875\%2990127-8

were shown to be erroneous two decades ago

http://dx.doi.org/10.1080/07315724.1995.10718483

http://www.mv.helsinki.fi/home/hemila/H/HH_1995.pdf

https://helda.helsinki.fi/handle/10138/42358

http://dx.doi.org/10.1016/S0899-9007\%2896\%2900223-7

http://www.mv.helsinki.fi/home/hemila/H/HH_1996_NUT.pdf

https://helda.helsinki.fi/handle/10138/225877

https://helda.helsinki.fi/handle/10138/20335 (pp. 36-45)

The Karlowski (1975) trial [10]

http://dx.doi.org/10.1001/jama.1975.03240220018013

was shown to be analyzed erroneously also two decades ago:

http://dx.doi.org/10.1016/0895-4356\%2896\%2900189-8

http://www.mv.helsinki.fi/home/hemila/H/HH 1996 JCE.pdf

https://helda.helsinki.fi/handle/10138/225872

http://dx.doi.org/10.1016/0895-4356\%2896\%2900190-4

http://dx.doi.org/10.1016/0895-4356\%2896\%2900191-6

http://www.mv.helsinki.fi/home/hemila/H/HH_1996_JCE2.pdf

https://helda.helsinki.fi/handle/10138/225873

http://dx.doi.org/10.1002/sim.2347

http://www.mv.helsinki.fi/home/hemila/H/2006 L SIM.pdf

https://helda.helsinki.fi/handle/10138/228098

https://helda.helsinki.fi/handle/10138/20335 (pp. 21-27)

These references are listed in our Cochrane review. Thus, had Vorilhon read our Cochrane review, they would have seen that their references [8-10] were erroneous in the context.

Authors of any meta-analysis should take some time to familiarize themselves with the field. 